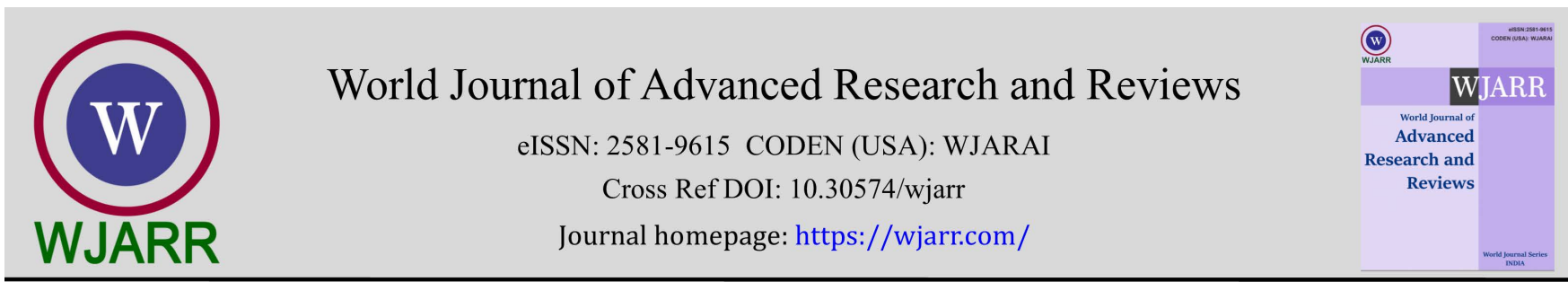

(RESEARCH ARTICLE)

\title{
Prevention of doxorubicin-induced haematotoxicity by turmeric in Wistar rats
}

\author{
Joshua Charles Isirima ${ }^{1}$ and Dorcas Okayo Okoroafor ${ }^{2}$ \\ ${ }^{1}$ Department of Biomedical Technology, School of Science Laboratory Technology, University of Port Harcourt, \\ Choba-Port Harcourt, 500272, Rivers State, Nigeria. \\ 2 Department of Biomedical Technology, School of Science Laboratory Technology, University of Port Harcourt, \\ Choba-Port Harcourt, 500272, Rivers State, Nigeria.
}

World Journal of Advanced Research and Reviews, 2021, 09(03), 096-108

Publication history: Received on 02 February 2021; revised on 05 March 2021; accepted on 07 March 2021

Article DOI: https://doi.org/10.30574/wjarr.2021.9.3.0084

\begin{abstract}
Doxorubicin is a known anticancer drug used in treatment of various cancers including leukemias, lymphomas, softtissue sarcomas and solid tumors. Doxorubicin exerts its toxicity on the blood by causing bone marrow suppression, myelosuppression, pronounced marrow depression and bone marrow depletion, and hypoplasia This study investigated the effect of turmeric on the haematological parameters in doxorubicin-induced oxidative stress in Wistar rats. 54 adult Wistar rats were divided into 9 groups of six animals each. Group 1 animals served as control (normal saline), group 2 animals served as negative control, and received doxorubicin, group 3 animals were given doxorubicin and turmeric, group 4 animals received doxorubicin and vitamin $\mathrm{C}$, group 5 animals received doxorubicin and vitamin E, group 6 animals received doxorubicin, vitamins $C$ and turmeric, group 7 animals received doxorubicin, vitamin $E$ and turmeric, while group 8 animals received doxorubicin, vitamin $C$ and vitamin E and finally, group 9 animals receive doxorubicin, vitamin $\mathrm{C}$, vitamin $\mathrm{E}$ and turmeric. The experiment lasted for 28 days and blood samples were collected from each animal from the various groups for haematological assay. Doxorubicin caused a significant decrease in the serum levels of white blood cell count, neutrophil count, lymphocyte count, monocyte count, platelet count, red blood cell count, hemoglobin concentration, hematocrit and mean corpuscular volume. These changes were prevented by turmeric alone or in combined concomitant administration with vitamins $\mathrm{C}$ and or $\mathrm{E}$ and doxorubicin
\end{abstract}

Keywords: Haematotoxicity; Doxorubicin; Turmeric; Wistar rats

\section{Introduction}

Standard cancer treatments include surgery, chemotherapy, and radiotherapy. However, these have many complications and problems for patients $[1,2]$. Chemotherapy is used for advanced cancers and multiple metastases because it is the only means by which cancer cells can be destroyed throughout the body [2]. Doxorubicin is an anthracycline antibiotic with proven antineoplastic activity against a broad range of tumors $[3,4]$. It is most often used in acute leukemia and lymphoma, and organ cancers of the lung, breast, bladder, stomach, thyroid and reproductive system [2,5] and vomiting is the most common side effect from doxorubicin in its injectable form. Doxorubicin also disrupts the production of red blood cells and can cause blood clotting disorders, anemia and leukopenia, thus according to Cortes et al., [6], its effect on blood parameters should be closely monitored during chemotherapy. Its use can be associated with a variety of toxicoses, including myelosuppression, enterocolitis, alopecia, and cardiomyopathy [7, 8 and 9]. Doxorubicin administration has been associated with dose-related decreases in hematocrit, hemoglobin, and red blood cell numbers in dogs, rabbits, and humans [9, 10, and 11]. Several researchers have reported adverse effects of doxorubicin administration on the haematological parameters. In one study aimed at evaluating the effect of

*Corresponding author: Joshua, Charles Isirima

Department of Biomedical Technology, School of Science Laboratory Technology, University of Port Harcourt, Choba-Port Harcourt, 500272, Rivers State, Nigeria.

Copyright (C) 2021 Author(s) retain the copyright of this article. This article is published under the terms of the Creative Commons Attribution Liscense 4.0. 
doxorubicin on haematological and blood biochemistry profile of health dogs it was reported that there was a significant decrease in total leucocyte count, total erythrocyte count and packed cell volume [12]. The researchers associated these changes to bone marrow suppression by doxorubicin. This was because scholars like Mac Donald, [13] reported that bone marrow cells divide very rapidly because of their high growth fraction and that the activity of most anticancerous drugs was greatest in tissues with a high growth fraction. According to Anil et al., [12], other researchers observed similar effects with doxorubicin in dogs undergoing chemotherapy. Because of the importance of doxorubicin in cancer treatment, it has become increasingly essential to find pharmacological remedies with protective effects against doxorubicin induced adverse effects.

Turmeric is a golden spice derived from the rhizome of the Curcuma longa plant, which belongs to the Zingiberaceae family [14]. Among the phytochemical constituents found in turmeric, curcumin is the one mostly reported to possess antioxidant properties. Curcumin possesses anti-inflammatory, immunomodulatory, and antiatherogenic activities and is a potent inhibitor of various reactive oxygen-generating enzymes $[15,16]$. Curcumin is a potent scavenger of reactive oxygen species including superoxide anion radicals and hydroxyl radicals. It has also been reported to inhibit erythrocyte lipid peroxidation [17]. Curcumin administration attenuated the arsenic, gentamicin, and acetaminopheninduced oxidative stress in rats $[18,19]$. Curcumin also prevented free radical formation-induced myocardial ischemia and paraquat induced lung injury in rats [20]. Furthermore, curcumin protected against diazinon-induced toxicity in blood, liver, and erythrocyte of male Wistar rats [21]. Curcumin is a potent anti-oxidant and free radical scavenger [22]. It inhibits lipid peroxidation (Sreejayan-Rao 1994) and also inhibits Nitric Oxide Synthase (NOS) over-expression [23, 24]. Also, Isirima and Christian [25], had reported the anti-oxidant potentials of turmeric. In their study, they found that turmeric demonstrated anti-oxidant properties my reversing the significant reduction in the serum concentration of SOD, GPx, CAT, GSH and TAS as well as the increase serum level of MDA, caused by doxorubicin.

\section{Methods}

\subsection{Animals}

54 adult Wistar rats of either sex weighing $200 \mathrm{~g}$ to $300 \mathrm{~g}$ were obtained from animal house of Department of Pharmacology, Faculty of Basic Medical Sciences, College of Health Sciences, University of Port Harcourt, Nigeria. All animals were allowed two weeks acclimatization in the same facility before the study commenced. They were all allowed free access food and tap water and were exposed to natural light-dark cycle and room temperature. All animals were handled according to standard protocols for the use of laboratory animals [26].

\subsection{Sample collection}

The root of turmeric plant was obtained from fruit garden within PH metropolis and was thoroughly washed to remove all dust particles, identified and authenticated at herbarium unit, by Dr. EkekeChimezie (Ph.D.) in the department of plant science and biotechnology, Faculty of Sciences, University of Port Harcourt, River State.

\subsection{Extraction Method}

The root of the plant was left to dry at room temperature between $32-350 \mathrm{C}$ after collection and cleaning until they attained a constant weight. The extraction method that was used was adopted from Hanan et al, [27] which is the cold maceration extraction protocol, with minute adjustments. The powdered turmeric root bark of about 50g was soaked in $70 \%$ ethanol of about $1000 \mathrm{ml}$ in a 2 litre flask and mixed forcefully at $1 \mathrm{hr}$ intermission, for $12 \mathrm{hrs}$ and allowed to settle over-night (35oC) to allow for adequate extraction. Subsequently, the concoction was filtered by means of a filter paper with pore size of 0.45 milli-pore. The concentration of the extract was increase using rotary evaporation process at $40 \mathrm{oC}$ and $200 \mathrm{rpm}$. The final semi-solid extract was obtained by drying the content of the rotary evaporator over a steam bath at $40 \mathrm{oC}$. The resultant extract obtained $23 \%$ yield, was kept safe at room temperature in desiccators, until it was needed for the study.

\subsection{Experimental Design}

54 adult Wistar rats were divided into nine groups of six animals each. Group 1 animals served as control (normal saline $0.2 \mathrm{ml}$ ), group 2 animals served as negative control, and received Doxorubicin (DOX), group 3 animals were given DOX and turmeric, group 4 animals received DOX and vitamin C, group 5 animals received DOX and vitamin E, group 6 animals received DOX, vitamins $C$ and turmeric, group 7 animals received DOX, vitamin E and turmeric, while group 8 animals received DOX, vitamin $\mathrm{C}$ and vitamin $\mathrm{E}$ and finally, group 9 animals receive DOX, vitamin $\mathrm{C}$, vitamin $\mathrm{E}$ and turmeric. The animals were administered the following doses of the drugs and extract; vitamin $\mathrm{C}$ was given at a dose of $90 \mathrm{mg} / 70 \mathrm{~kg} /$ day, Vitamin E was give at a dose of $22.4 \mathrm{IU} / 70 \mathrm{~kg} /$ day, DOX was administered at a dose of $10-20 \mathrm{mg} / \mathrm{m} 2$ 
once a week, while turmeric was administered at a dose of $500 \mathrm{mg} / \mathrm{kg} /$ day. The sequence of administration of these drugs as describe above continued for a period of 28 days, but the animals were sacrificed under diethyl ether anesthesia, on day 14 and day 28th. Blood samples were collected from each animal from the various groups for haematological analysis. The animals were grouped as shown below;

Group 1 = Control, Group 2 = Doxorubicin (DOX), Group $3=$ DOX + Turmeric (T), Group $4=$ DOX + Vitamin C (C), Group 5= DOX + Vitamin E (E), Group $6=$ DOX + C + T, Group $7=$ DOX + E+T, Group $8=$ DOX + C+E, Group $9=\mathrm{DOX}+\mathrm{C}+\mathrm{E}+\mathrm{T}$.

\subsection{Hematological Analysis}

Hematological analysis was carried out as described by Ghai, [28], within $24 \mathrm{~h}$ of sample collection, to determine the levels of red blood cells (RBC) and white blood cells (WBC), differential leucocyte (DLC), platelet, haemoglobin concentration $(\mathrm{Hb})$, and red cell indices, including mean corpuscular hemoglobin $(\mathrm{MCH})$, mean corpuscular volume (MCV) and mean cell hemoglobin concentration (MCHC).

\subsection{Statistical analysis}

Mean values $\pm S$. E. M. were calculated for each parameter. For the determination of significant differences, Means were compared using the oneway Analysis of variance (ANOVA) test and the significance between the study groups were tested by employing the Post Hoc, multiple comparison test with Dunnett. P values $<0.05$ were considered as a level of statistical significance.

\section{Results}

Figure 1 presents the effect of turmeric on total white blood cell count $\left[(\mathrm{WBC})\left(\mathrm{x} 10^{3} / \mu \mathrm{l}\right)\right]$ in doxorubicin-inducedtoxicity in Wistar rats after 14 days of simultaneous drug treatment, showing that doxorubicin (Dox) caused a significant decrease $(p \leq 0.05)$ in the total white blood cell count $(3.20 \pm 0.33)$ when compared to the control $(6.93 \pm 0.24)$. This decrease was reversed towards normal by turmeric alone $(5.54 \pm 0.21)$ or in combination with vitamins $\mathrm{C}$ and $\mathrm{E}$ (6.34 \pm 0.61$)$. These observations were similar to those in figure 2 with total white blood cell count values of $(1.43 \pm 0.28)$, $(6.83 \pm 0.15)$ and $(5.94 \pm 0.15)$ for doxorubicin, control and turmeric respectively, after 28 days of concomitant drug treatment. Figure 3 presents the effect of turmeric on neutrophil count $\left(\mathrm{x} 10^{3} / \mu \mathrm{l}\right)$ in doxorubicin-induced-toxicity in Wistar rats after 14 days of concomitant drug treatment, showing that doxorubicin (Dox) caused a significant decrease $(p \leq 0.05)$ in the serum level of neutrophil count $(0.09 \pm 0.02)$ when compared to the control $(0.21 \pm 0.06)$. This decrease was reversed towards normal by turmeric alone $(0.15 \pm 0.02)$ or in combination with vitamins $\mathrm{C}$ and $\mathrm{E}(0.20 \pm 0.04)$. These observations were similar to those in figure 4 with neutrophil count of $(0.04 \pm 0.01),(0.21 \pm 0.06)$ and $(0.18 \pm 0.03)$ for doxorubicin, control and turmeric respectively, after 28 days of simultaneous drug treatment. Figure 5 presents the effect of turmeric on lymphocyte count $\left(\mathrm{x} 10^{3} / \mu \mathrm{l}\right)$ in doxorubicin-induced-toxicity in Wistar rats after 14 days of simultaneous drug treatment, showing that doxorubicin (Dox) caused a significant decrease $(p \leq 0.05)$ in the serum level of lymphocyte count $(3.16 \pm 0.75)$ when compared to the control $(6.13 \pm 0.20)$. This decrease was reversed towards normal by turmeric alone $(5.21 \pm 0.24)$ or in combination with vitamins $C$ and $E(6.10 \pm 0.22)$. These observations were similar to those in figure 6 with lymphocyte count of $(3.04 \pm 0.15),(6.13 \pm 0.20)$ and $(5.58 \pm 0.51)$ for doxorubicin, control and turmeric respectively, after 28 days of simultaneous drug treatment. Figure 7 presents the effect of turmeric on monocyte count $\left(\mathrm{x}_{10} 0^{3} / \mu \mathrm{l}\right)$ in doxorubicin-induced-toxicity in Wistar rats after 14 days of simultaneous drug treatment, showing that doxorubicin (Dox) caused a significant decrease $(\mathrm{p} \leq 0.05)$ in the serum level of monocyte count $(0.09 \pm 0.03)$ when compared to the control $(0.22 \pm 0.02)$. This decrease was reversed towards normal by turmeric alone $(0.17 \pm 0.05)$ or in combination with vitamins $C$ and $\mathrm{E}(0.20 \pm 0.08)$. These observations were similar to those in figure 8 with monocyte count of $(0.08 \pm 0.01),(0.22 \pm 0.02)$ and $(0.18 \pm 0.07)$ for doxorubicin, control and turmeric respectively, after 28 days of concomitant drug treatment. Figure 9 presents the effect of turmeric on platelet count $\left(\mathrm{x} 10^{3} / \mu \mathrm{l}\right)$ in doxorubicin-induced-toxicity in Wistar rats after 14 days of concomitant drug treatment, showing that doxorubicin (Dox) caused a significant decrease $(\mathrm{p} \leq 0.05)$ in the level of platelet $(239.00 \pm 8.01)$ when compared to the control $(652.33 \pm 4.10)$. This decrease was reversed towards normal by turmeric alone $(542.73 \pm 8.11)$ or in combination with vitamins $C$ and $E(614.41 \pm 4.19)$. These observations were similar to those in figure 10 with platelet count of (217.00 \pm 9.29$),(652.33 \pm 4.10)$ and $(552.83 \pm 7.11)$ for doxorubicin, control and turmeric respectively, after 28 days of simultaneous drug treatment. Figure 11 presents the effect of turmeric on red blood cell count $\left[(\mathrm{RBC})\left(\mathrm{x} 10^{6} / \mu \mathrm{l}\right)\right] \mathrm{in}$ doxorubicin-induced-toxicity in Wistar rats after 14 days of concomitant drug treatment, showing that doxorubicin (Dox) caused a significant decrease $(\mathrm{p} \leq 0.05)$ in the level of red blood cell count $(3.17 \pm 0.26)$ when compared to the control $(8.35 \pm 0.64)$. This decrease was reversed towards normal by turmeric alone $(3.58 \pm 0.21)$ or in combination with vitamins $C$ and $E(8.29 \pm 0.42)$. These observations were similar to those in figure 12 with red blood cell count of $(2.97 \pm 0.09)$, $(8.35 \pm 0.64)$ and $(8.30 \pm 0.81)$ for doxorubicin, control and turmeric respectively, after 28 days of simultaneous drug treatment. Figure 13 presents the effect of turmeric on hemoglobin concentration $[(\mathrm{Hgb})(\mathrm{g} / \mathrm{dl})]$ in 
doxorubicin-induced-toxicity in Wistar rats after 14 days of simultaneous drug treatment, showing that doxorubicin (Dox) caused a significant decrease $(\mathrm{p} \leq 0.05)$ in the hemoglobin concentration $(6.20 \pm 0.75)$ when compared to the control $(16.20 \pm 1.15)$. This decrease was reversed towards normal by turmeric alone $(14.27 \pm 1.31)$ or in combination with vitamins $C$ and $E(16.06 \pm 1.13)$. These observations were similar to those in figure 14 with hemoglobin concentration of $(5.47 \pm 0.58),(16.20 \pm 1.15)$ and $(14.78 \pm 1.18)$ for doxorubicin, control and turmeric, after 28 days of concomitant drug treatment. Figure 15 presents the effect of turmeric on hematocrit [(HCT)(\%)]in doxorubicininduced-toxicity in Wistar rats after 14 days of simultaneous drug treatment, showing that doxorubicin (Dox) caused a significant decrease $(\mathrm{p} \leq 0.05)$ in the hematocrit level $(15.67 \pm 1.20)$ when compared to the control $(43.00 \pm 1.15)$. This decrease was reversed towards normal by turmeric alone $(36.57 \pm 1.28)$ or in combination with vitamins $\mathrm{C}$ and $\mathrm{E}$ (41.58 \pm 1.25$)$. These observations were similar to those in figure 16 with hematocrit levels of $(14.21 \pm 0.58)$, $(43.00 \pm 1.15)$ and $(38.46 \pm 1.19)$ for doxorubicin, control and turmeric, after 28 days of concomitant drug treatment. Figure 17 presents the effect of turmeric on mean corpuscular volume $\left[(\mathrm{MCV}) \mathrm{fL}\left(\mu \mathrm{m}^{3}\right)\right]$ in doxorubicin-induced-toxicity in Wistar rats after 14 days of simultaneous drug treatment, showing that doxorubicin (Dox) caused a significant decrease $(\mathrm{p} \leq 0.05)$ in the mean corpuscular volume $(18.07 \pm 0.58)$ when compared to the control $(51.67 \pm 1.45)$. This decrease was reversed towards normal by turmeric alone $(46.61 \pm 1.32)$ or in combination with vitamins $\mathrm{C}$ and $\mathrm{E}$ (49.94 \pm 1.18$)$. These observations were similar to those in figure 18 with mean corpuscular volume of $(16.13 \pm 0.81)$, $(51.67 \pm 1.45)$ and $(47.72 \pm 1.19)$ for doxorubicin, control and turmeric, after 28 days of concomitant drug treatment.

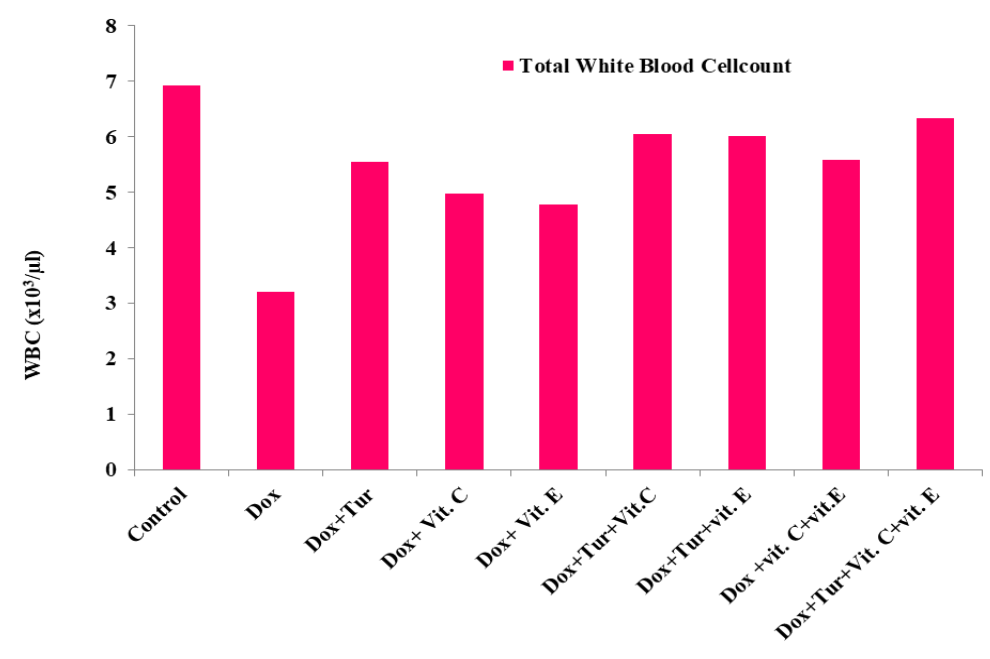

Figure 1 Effect of turmeric on Total White Blood Cellcount (WBC) $\left(x 10^{3} / \mu l\right)$ in doxorubicin-induced toxicity in Wistar Rats.

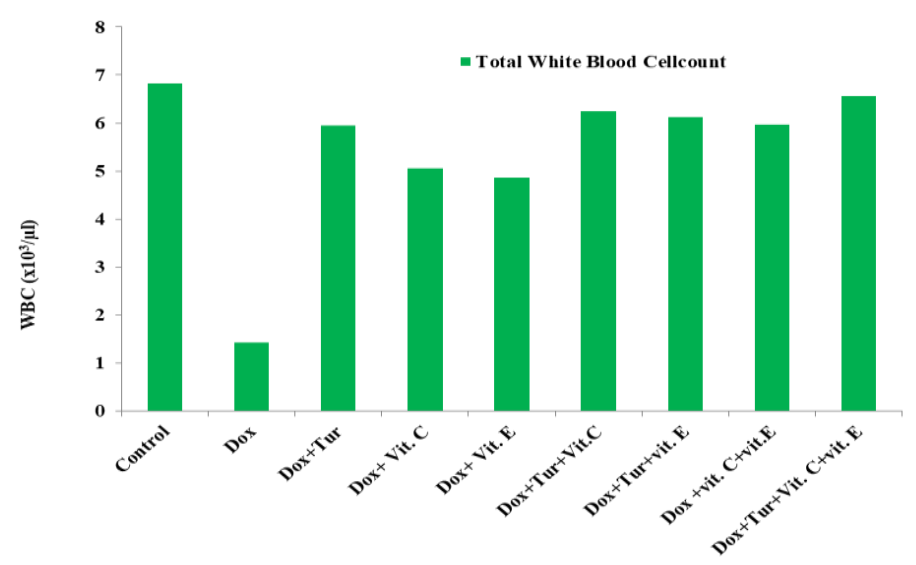

Figure 2 Effect of turmeric on Total White Blood Cellcount (WBC) $\left(\mathrm{x} 10^{3} / \mu \mathrm{l}\right)$ in doxorubicin-induced toxicity in Wistar Rats 28 days of drug treatment. 


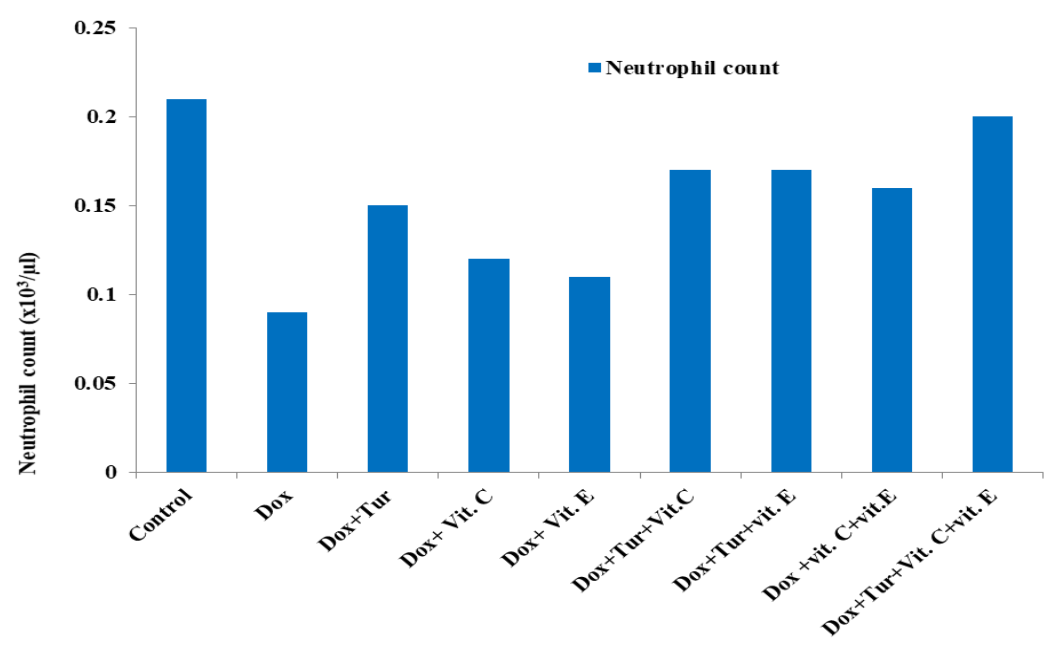

Figure 3 Effect of turmeric on Neutrophil count $\left(\mathrm{x}^{3} 0^{3} / \mu \mathrm{l}\right)$ in doxorubicin-induced toxicity in Wistar Rats 14 days of drug treatment.

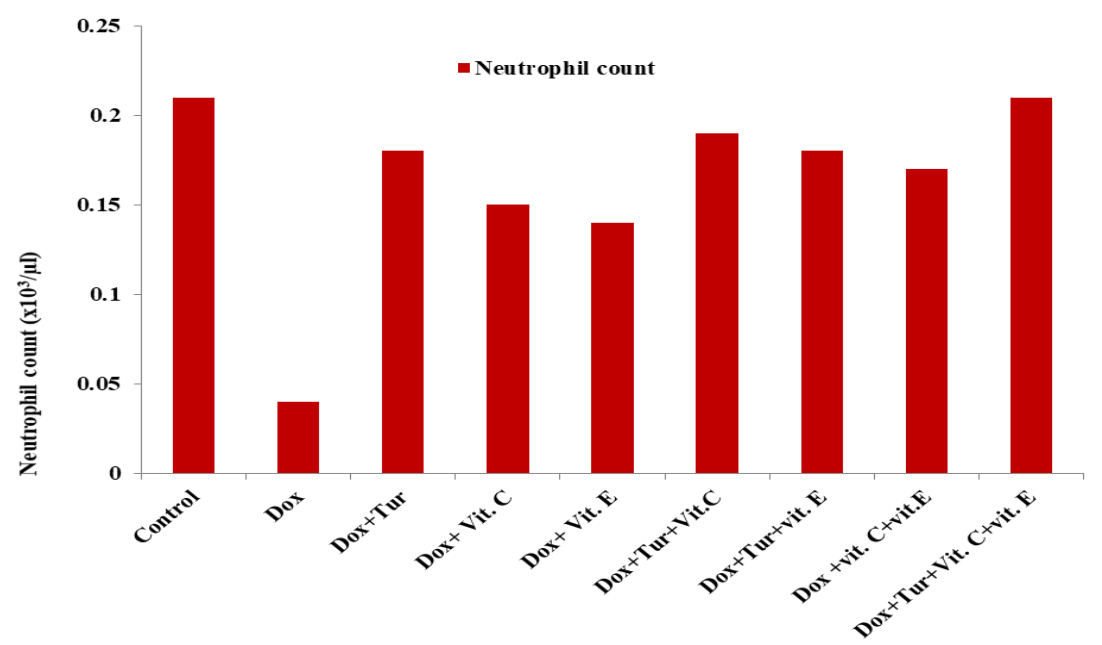

Figure 4 Effect of turmeric on Neutrophil count $(\mathrm{x} 103 / \mu \mathrm{l})$ in doxorubicin-induced toxicity in Wistar Rats 28 days of drug treatment.

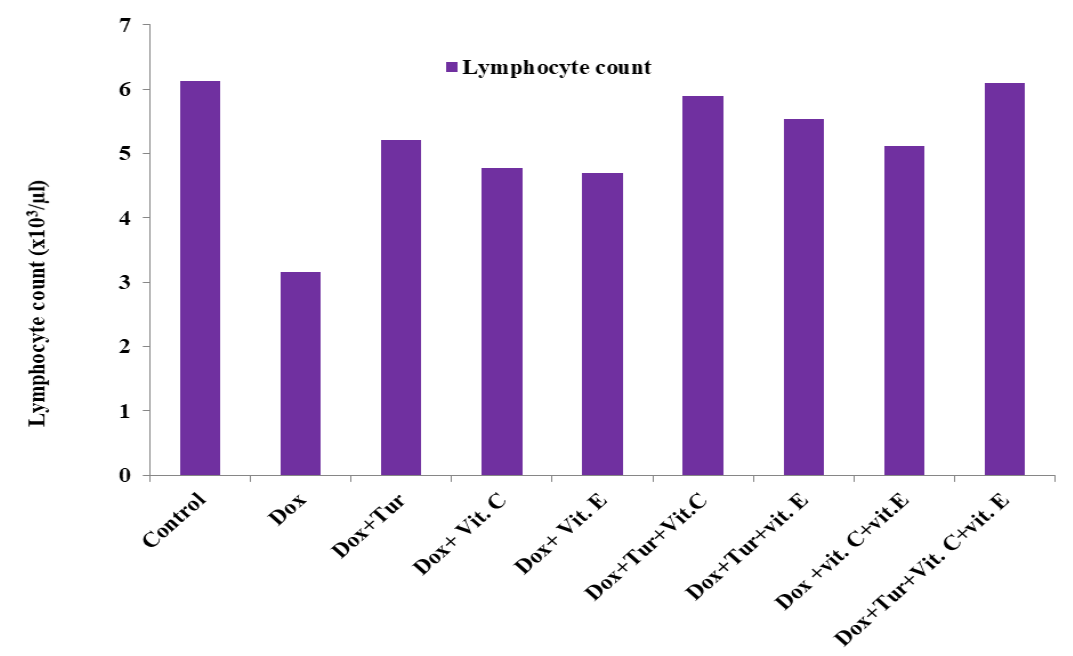

Figure 5 Effect of turmeric on Lymphocyte count $(\mathrm{x} 103 / \mu \mathrm{l})$ in doxorubicin-induced toxicity in Wistar Rats 14 days of drug treatment. 


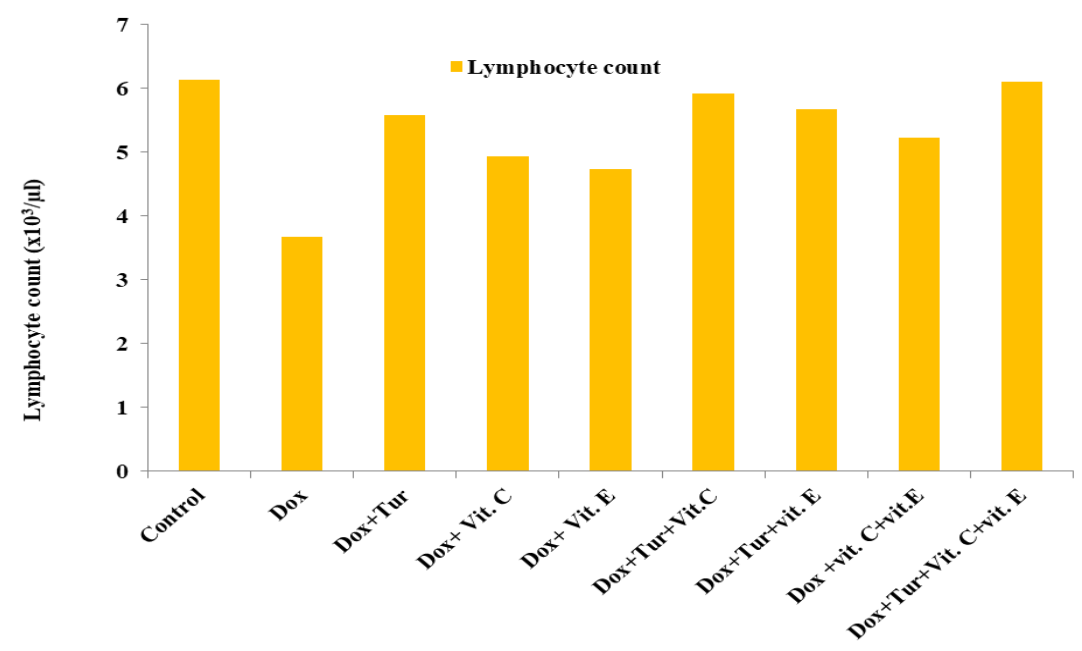

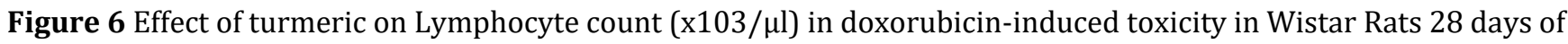
drug treatment.

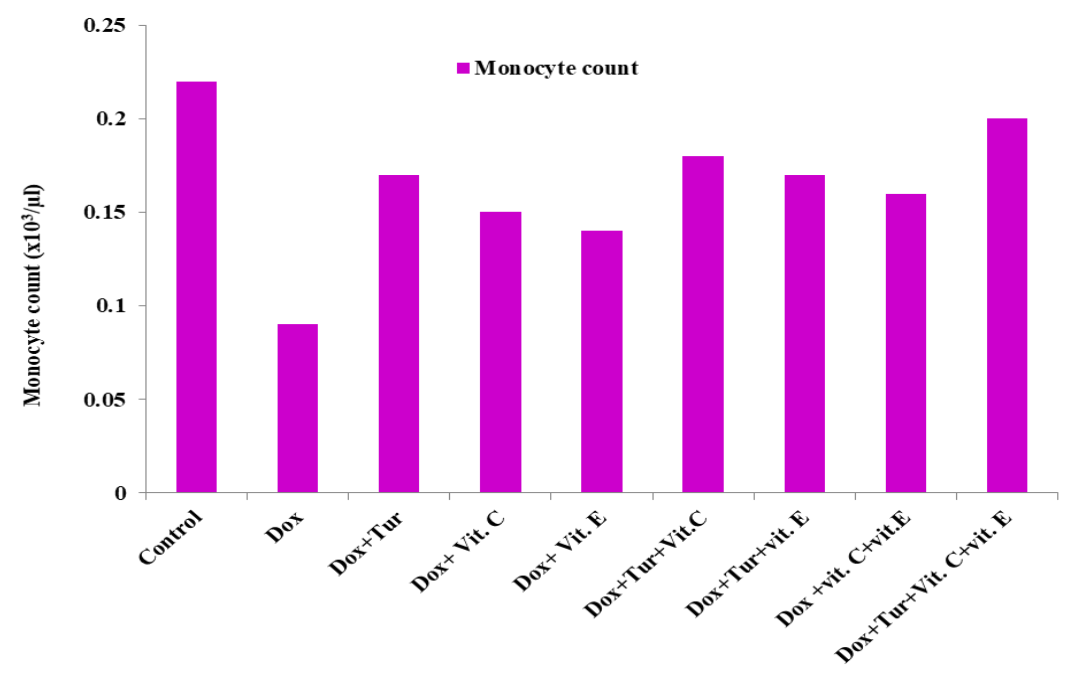

Figure 7 Effect of turmeric on Monocyte count (x103/ $\mu$ l) in doxorubicin-induced toxicity in Wistar Rats 14 days of drug treatment.

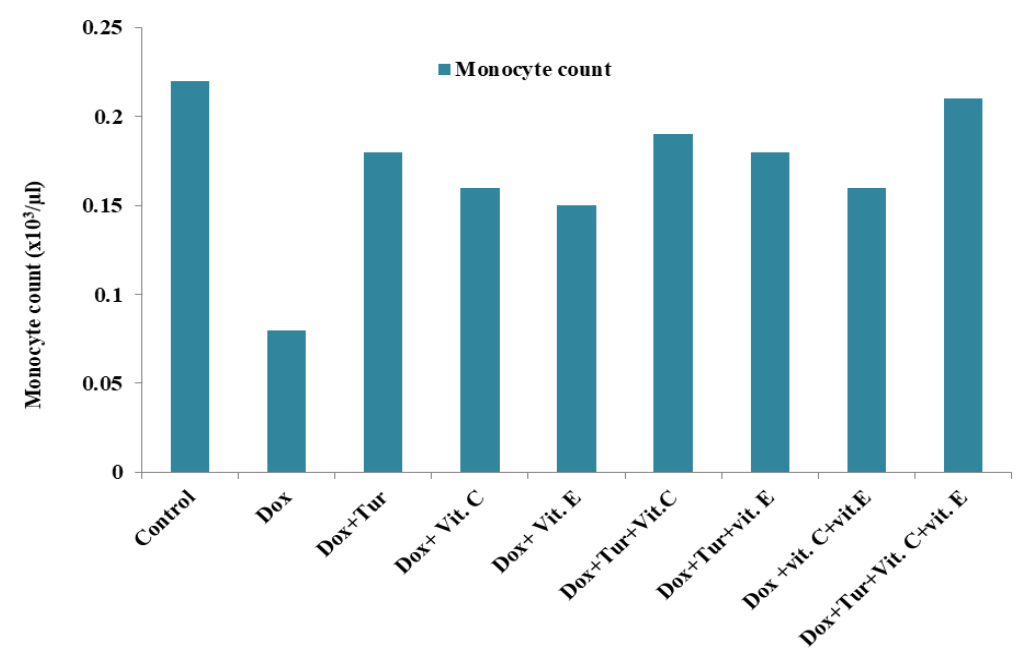

Figure 8 Effect of turmeric on Monocyte count (x103/ $\mu \mathrm{l})$ in doxorubicin-induced toxicity in Wistar Rats 28 days of drug treatment. 


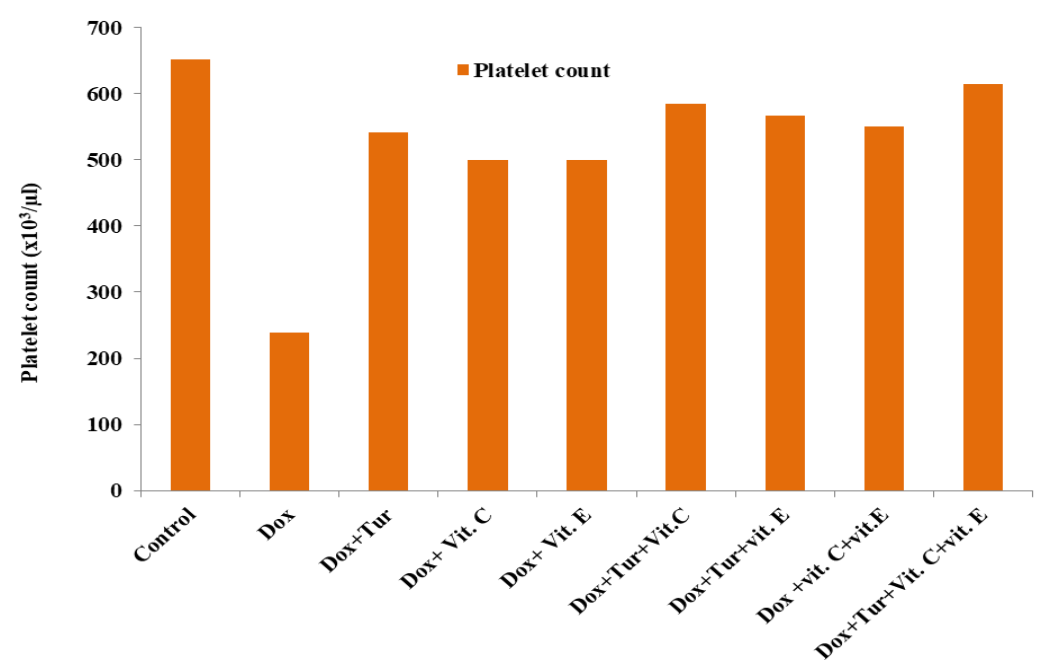

Figure 9 Effect of turmeric on Platelet count $(x 103 / \mu l)$ in doxorubicin-induced toxicity in Wistar Rats 14 days of drug treatment.

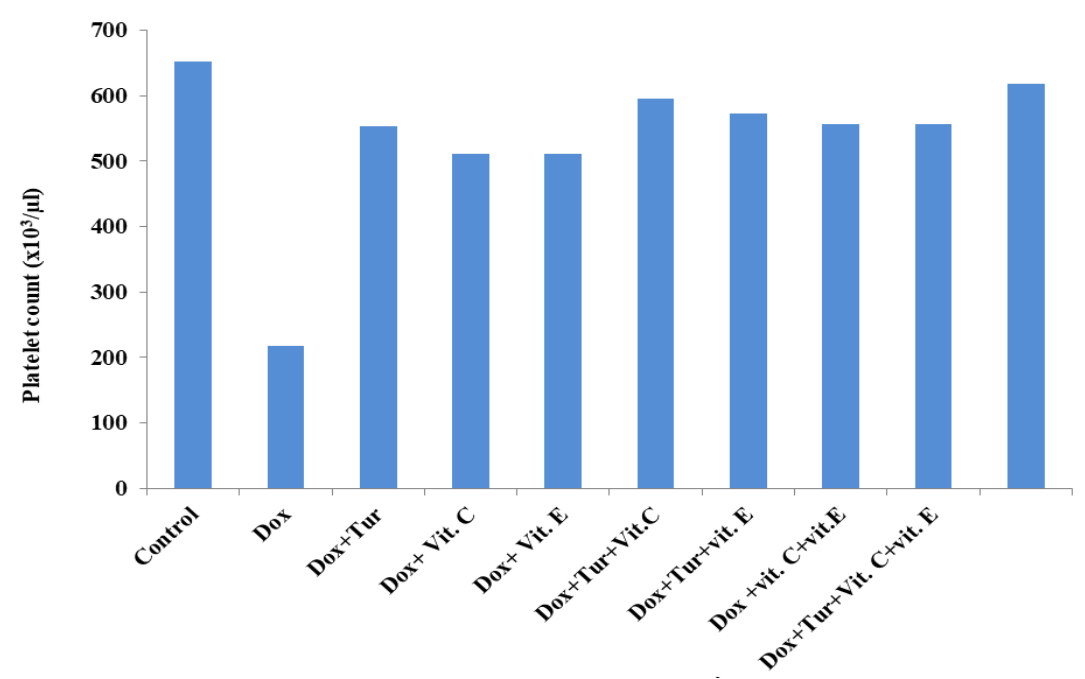

Figure 10 Effect of turmeric on Platelet count $(\mathrm{x} 103 / \mu \mathrm{l})$ in doxorubicin-induced toxicity in Wistar Rats 28 days of drug treatment.

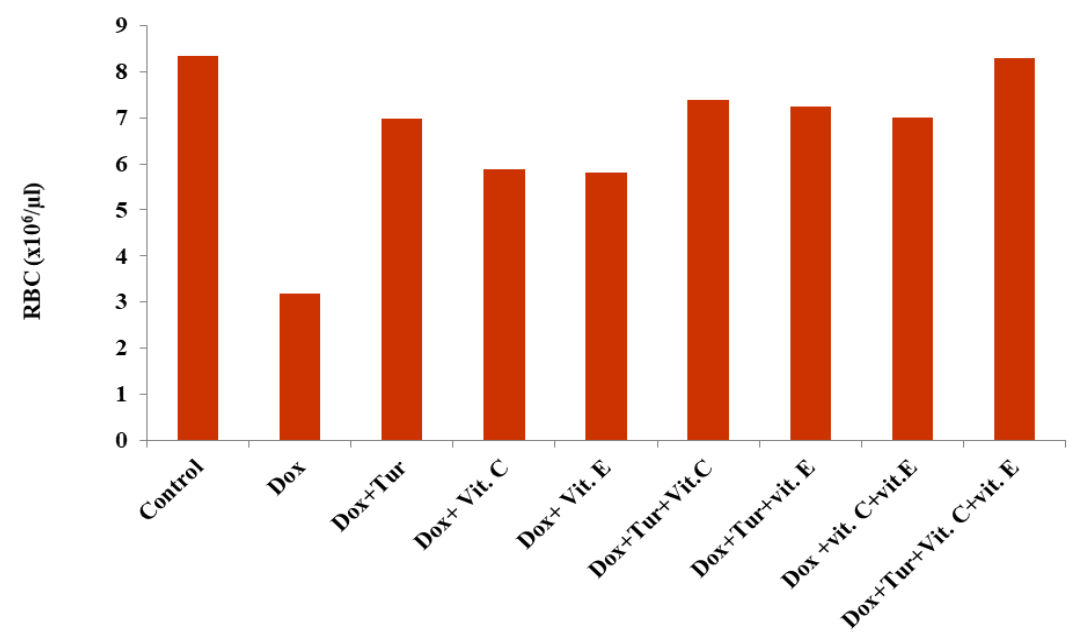

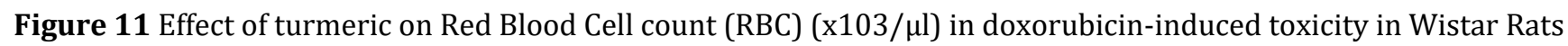
14 days of drug treatment. 


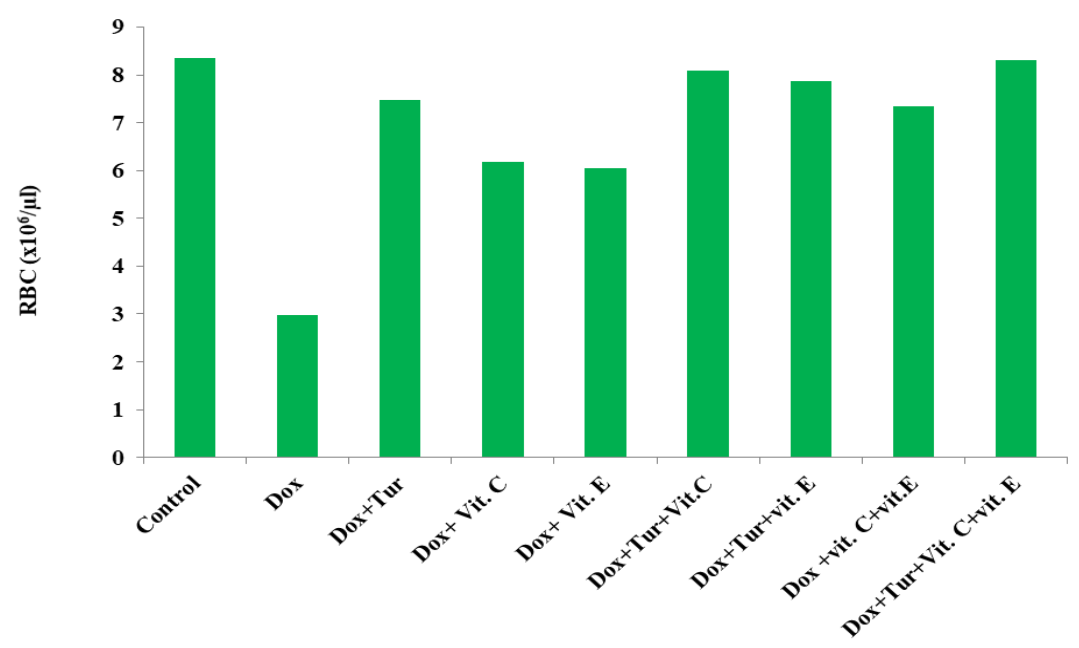

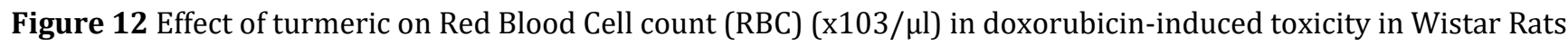
28 days of drug treatment.

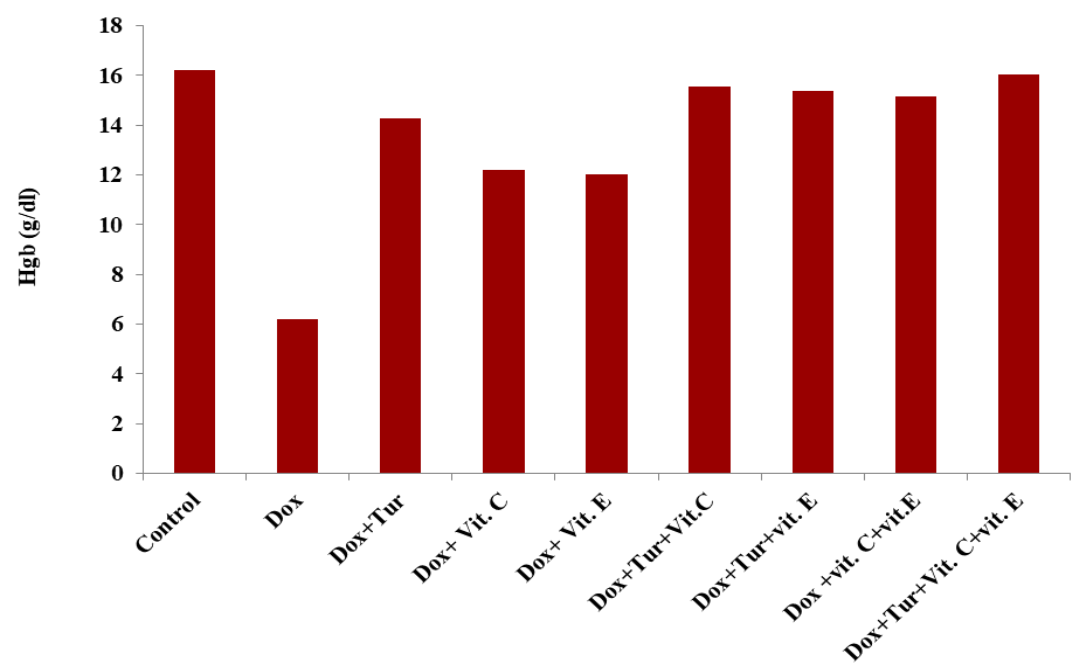

Figure 13 Effect of turmeric on Hemoglobin concentration (Hgb) (g/dl) in doxorubicin-induced toxicity in Wistar Rats 14 days of drug treatment.

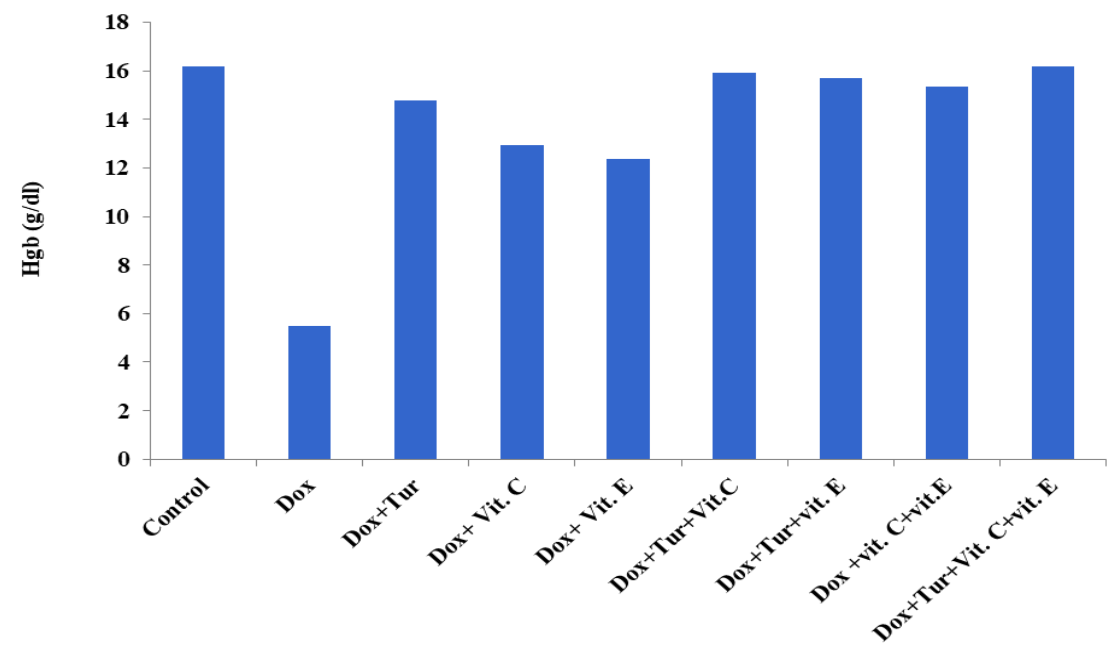

Figure 14 Effect of turmeric on Hemoglobin concentration (Hgb) (g/dl) in doxorubicin-induced toxicity in Wistar Rats 28 days of drug treatment. 


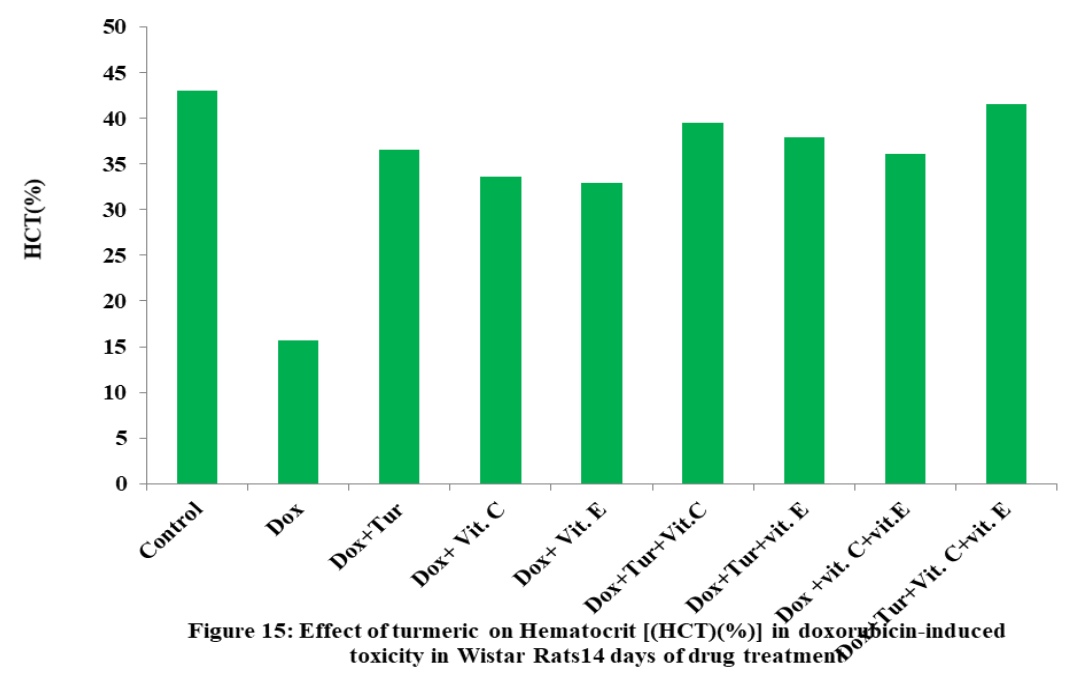

Figure 15 Effect of turmeric on Hemoglobin (HCT) (\%) in doxorubicin-induced toxicity in Wistar Rats 14 days of drug treatment.

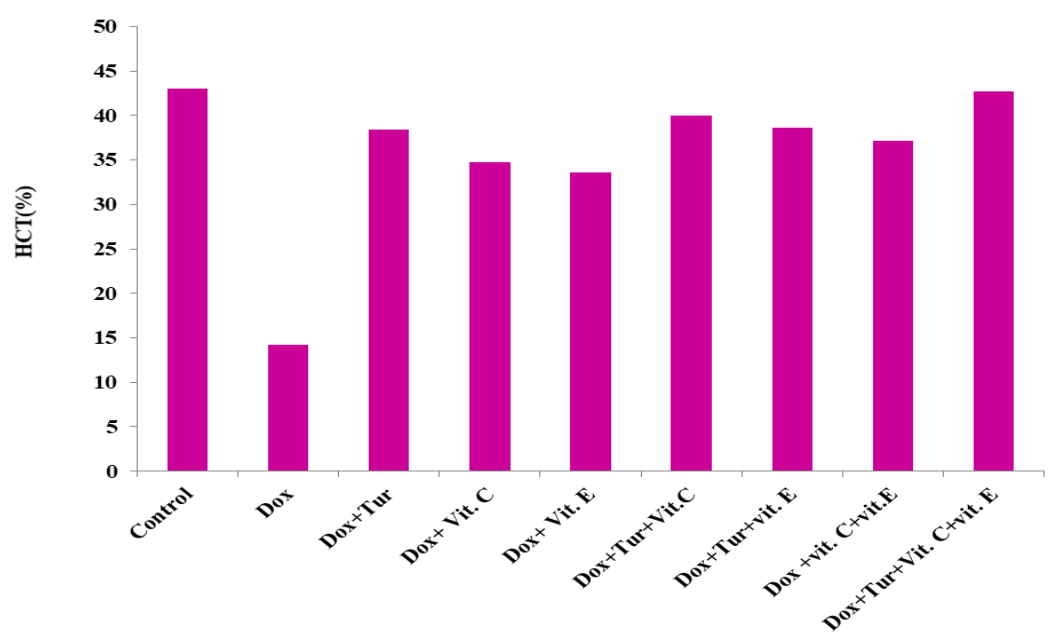

Figure 16 Effect of turmeric on Hemoglobin (HCT) (\%) in doxorubicin-induced toxicity in Wistar Rats 28 days of drug treatment.

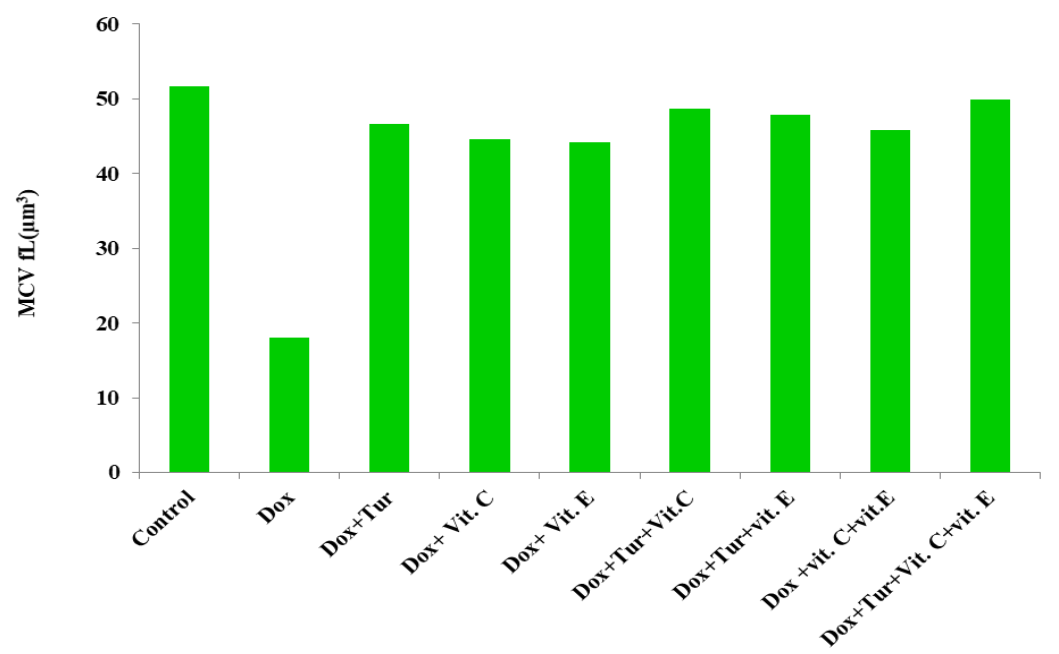

Figure 17 Effect of turmeric on Mean Corpuscular volume (mcv) $\left(\mu \mathrm{m}^{3}\right)$ in doxorubicin-induced toxicity in Wistar Rats 14 days of drug treatment 


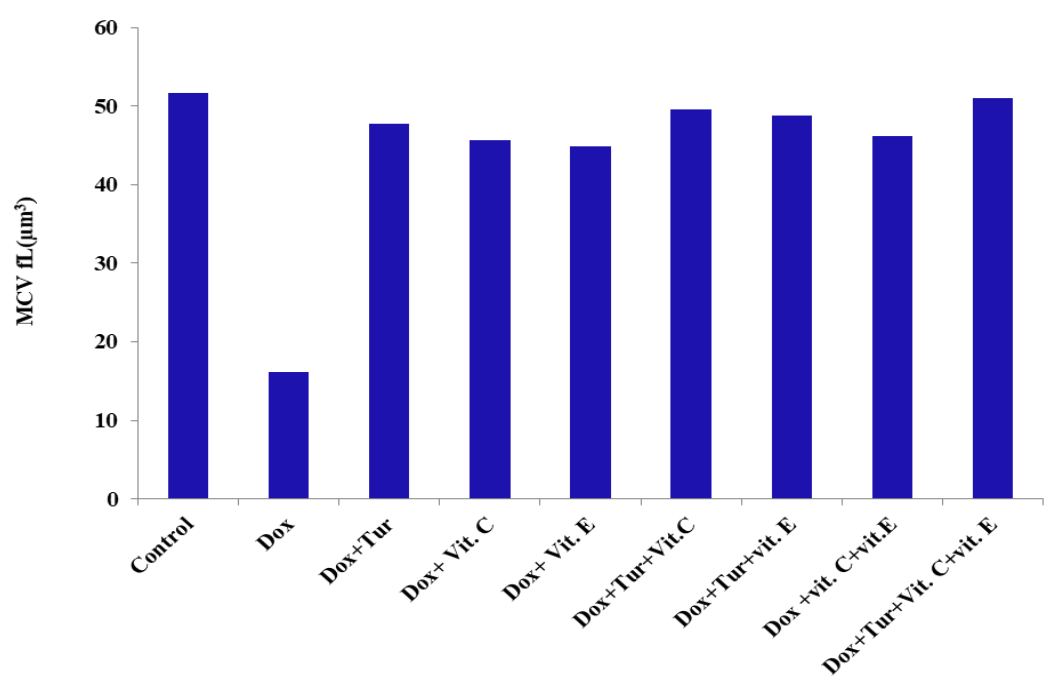

Figure 18 Effect of turmeric on Mean Corpuscular volume (mcv) $\left(\mu \mathrm{m}^{3}\right)$ in doxorubicin-induced toxicity in Wistar Rats 28 days of drug treatment.

\section{Discussion}

Doxorubicin administration to Wistar rats for 14 and 28 days caused a significant decrease in the serum levels of white blood cell count, neutrophil count, lymphocyte count, monocyte count, platelet count, red blood cell count, hemoglobin concentration, hematocrit and mean corpuscular volume. These findings are in agreement with the observations in other studies $[6,7,9,10,11$, and 12]. Several other researchers have also report similar effects of doxorubicin on haematology. Other reports record haemotoxicity in the mouse, describing a DOX-induced leucopenia (neutropenia and lymphocytopenia), in conjunction with reduced RBC/Hb/HCT and thrombocytopenia $[29,30]$. In the rabbit, leucopenia and neutropenia are described, with reduced $\mathrm{RBC} / \mathrm{Hb} / \mathrm{HCT}$ values (anaemia), reticulocytopenia and thrombocytopenia $[3,32]$. O'Keefe and Schaeffer [33] described neutropenia and thrombocytopenia in cats. Leucopenia, lymphocytopenia, reduced $\mathrm{RBC} / \mathrm{Hb} / \mathrm{HCT}$ (anaemia) and thrombocytopenia were recorded in the dog [9, 34, 11 and 35] in the pig, Van Vleet et al. [31] reported leucopenia, anaemia and thrombocytopenia. Studies have attributed the decrease in the haematological parameters to be as a result of disruption in production of red blood cells, anemia and leukopenia [6], or bone marrow suppression by doxorubicin [12], as was reported that myelosuppression is the principal dose-limiting toxicity [36, 10 and 37]. Doxorubicin causes pronounced marrow depression with peripheral blood leucopenia (granulocytopenia), thrombocytopenia and possible anaemia [38, 10 and 39]. Also, it has been reported that, bone marrow depletion/depression/hypoplasia have been frequently observed, for example in the mouse [40, 30], rat [35, 30]. This was believed to be so because bone marrow cells divide very rapidly because of their high growth fraction, Mac Donald, [13], and that the activity of most anticancerous drugs was greatest in tissues with a high growth fraction [13]. On the contrary, a simultaneous administration of turmeric alone or with vitamins $C$ and or $E$ and doxorubicin prevented these abnormal changes in the haematological indices. These protective ability of turmeric agrees with other those of the studies which attributed the effect of turmeric to be gue to the presence curcumin which is said to was also reported to have inhibit erythrocyte lipid peroxidation [17] and also to protect against diazinon-induced toxicity in blood, liver, and erythrocyte of male Wistar rats [21]. Turmeric is said to contains curcumin (77\%), the major component with other substances demethoxycurcumin (17\%) and bisdemethoxycurcumin (3\%) [41]. Curcumin is reported to possess anti-oxidant anti-inflammatory, immunomodulatory, antiatherogenic activities and is a potent inhibitor of various reactive oxygen-generating enzymes, and a scavenger of reactive oxygen species including superoxide anion radicals and hydroxyl radicals [15, 22, and 16]. It is also said to inhibit lipid peroxidation [42] and Nitric Oxide Synthase (NOS) over-expression $[23,24]$. This anti oxidant properties was demonstrated in rats by Isirima and Christian [25], who reported that turmeric prevented the significant reduction in the serum concentration of SOD, GPx, CAT, GSH and TAS as well as the increase serum level of MDA, caused by doxorubicin. Thus the haemato-protective effect of turmeric may be related to the potent anti-oxidant properties of curcumin. Thus turmeric presents a promising compliment for doxorubicin combine therapy which could be exploited in cancer chemotherapy after due clinical trials.

\section{Conclusion}

Doxorubicin caused a significant decrease in the serum levels of white blood cell count, neutrophil count, lymphocyte count, monocyte count, platelet count, red blood cell count, hemoglobin concentration, hematocrit and mean 
corpuscular volume in Wistar rats. These abnormal haematological changes were prevented by administration of turmeric alone or in combination with vitamins $\mathrm{C}$ and or $\mathrm{E}$ and doxorubicin simultaneously.

\section{Compliance with ethical standards}

\section{Acknowledgments}

My sincere thanks goes to Mr. Moses Itugha of Anatomy Department, who was responsible for the preparation of the tissues for the histological study and Dr. J. S. Hart also of Anatomy Department, who was there to explain the different histological changes of the various tissues. I do appreciate all of you.

\section{Disclosure of conflict of interest}

There is no conflict of interest in connection with this paper

\section{Statement of ethical approval}

This study was duly approved by the ethical committee of the School of Science Laboratory Technology, University of Port Harcourt.

\section{Statement of informed consent}

This study does not involve human subject, hence there was no need of informed consent.

\section{References}

[1] da Silva SD, Ferlito A, Takes RP. Advances and applications of oral cancer basic research. Oral Oncol. 2011; 47: 783-91.

[2] Johansson S, Goldenberg D, Griffiths G. Elimination of HIV-1 infection by treatment with a doxorubicinconjugated anti-envelope antibody. AIDS. 2006; 20: 1911-15.

[3] Ogilvie, GK, Reynolds HA, Richardson RC,. Phase I1 evaluation of doxorubicin for treatment of various canine neoplasms. J Am Vet Med Assoc. 1989; 195:1580-1583.

[4] Calvert CA, Leifer CE. Doxorubicin for treatment of canine lymphosarcoma after development of resistance to combination chemotherapy. J Am Vet Med Assoc. 1981; 179:1011-1012.

[5] Nowak AK, Chow PK, Findlay M. Systemic therapy for advanced hepatocellular carcinoma: a review. Eur J Cancer. 2004; 40: 1474-84.

[6] Cortés-Funes H, Coronado C. Role of anthracyclines in the era of targeted therap. Cardiovasc Toxicol. 2007; 7: 5660.

[7] Ogilvie GK, Richardson RC, Curtis CR. Acute and shortterm toxicoses associated with the administration of doxorubicin to dogs with malignant tumors. J Am Vet Med Assoc. 1989; 195: 1584-1587.

[8] Van Vleet JF, Ferrans VJ. Clinical observations, cutaneous lesions, and ematologic alterations in chronic Adriamycin intoxication in dogs with and without vitamin E and selenium supplementation. Am J Vet Res. 1980; 41:691-699.

[9] Bertazzoli C, Chieli T, Ferni G. Chronic toxicity of Adriamycin: A new antineoplastic antibiotic. Toxicol Appl Pharmacol. 1972; 21:287-301.

[10] Blum RH, Carter SK. A new anticancer drug with significant clinical activity. Ann Intern Med. 1974; 80:249-59.

[11] Badylak SF, Van Vleet JF, Herman EH. Poikilocytosis in dogs with chronic doxorubicin toxicosis. Am J Vet Res. 1985; 46: 505-508.

[12] AnilL Sindhur, Ashok Kumar, RN Chaudhary, Deepak Kumar Tiwari,Naveen Prabha. Effect of doxorubicin on haematological and blood Biochemistry Profile of health Dogs Haryana Vet. June 2019; 58(1): 11-14.

[13] Mac Donald V. Chemotherapy: Managing side effects and safe handling, CVJ. 2009; 50: 665-668. 
[14] Gupta SC, B Sung JH, Kim S, Prasad S Li, BB Aggarwal. "Multitargeting by turmeric, the golden spice: From kitchen to clinic," Molecular Nutrition and Food Research. 2013; 57(9): 1510-1528.

[15] Ara'ujo CC, Ara'ujo,LL Leon. Biological activities of Curcuma longa L," Mem'orias do Instituto Oswaldo Cruz. 2001; 96(5): 723-728.

[16] Chainani-Wu N. "Safety and anti-inflammatory activity of curcumin: a component of tumeric (Curcuma longa)," Journal ofAlternative and ComplementaryMedicine. 2003; 9(1): 161-168.

[17] Borra SK, P Gurumurthy, M Mahendra, KM Jayamathi, CN Cherian,C Ram. "Antioxidant and free radical scavenging activity of curcumin determined by using different in vitro and ex vivo models," Journal of Medicinal Plants Research. 2013; 7(36): 2680-2690.

[18] El-Demerdash, FM, MI Yousef, FME Radwan. "Ameliorating effect of curcumin on sodium arsenite-induced oxidative damage and lipid peroxidation in different rat organs," Food and Chemical Toxicology. 2009; 47(1): 249-254.

[19] Cekmen M, YO Ilbey, E Ozbek, A Simsek, A Somay, C Ersoz. "Curcumin prevents oxidative renal damage induced by acetaminophen in rats," Food and Chemical Toxicology. 2009; 47(7): 1480-1484.

[20] Manikandan P, M Sumitra, S Aishwarya, BM Manohar, B Lokanadam, R Puvanakrishnan. "Curcumin modulates free radical quenching in myocardial ischaemia in rats," The International Journal of Biochemistry \& Cell Biology. 2004; 36(10): 1967-1980.

[21] Messarah M, W Amamra, A Boumendjel. "Ameliorating effects of curcumin and vitamin E on diazinon-induced oxidative damage in rat liver and erythrocytes," Toxicology and Industrial Health. 2013; 29(1): 77-88.

[22] Fujisawa S, T Atsumi, M Ishihara,Y Kadoma. Cytotoxicity, reactive oxygen species-generating activity and radical scavenging activity of curcumin and other related compounds. Anti-Cancer Res. 2004; 24: 563-570.

[23] Spina GA. The dual role of nitric oxide i islet B-cells. News Physiol. Sci. 1999; 14:49-54

[24] Pan MH, SY Lin-Shiiau,JK Lin. Comparative studies on the suppression of nitric oxide synthase by curcumin and its hydrogenated metabolites through down-regulation of Ikappa Bkinas and NFkappaB activation in macrophages. Biochem. Pharmacol. 2000; 60: 1665-1676.

[25] Isirima, Joshua Charles and Christian Ifeanyi Uruaka. Evaluation of Anti-Oxidants Potential of Turmeric, Vitamins $\mathrm{C}$ and E in Doxorubicin-Induced Oxidative Stress in Wistar Rat., Int. Journal of Pharmaceutical Sciences and Medicine (IJPSM). 2021; 6(2): 12-23.

[26] National Institute of Health. Public health service policy on humane care and use of laboratory animals; Office of the laboratory animal welfare, USA. 2002; 1-19.

[27] Hanan B, Akram H, Hassan R, Ali H, Zeinab S, Bassam B. Techniques for the Extraction of Bioactive Compounds from Lebanese Urtica dioica. Maceration method. American Journal of Phytomedicine and Clinical Therapeutics. 2013; 6: 507-513.

[28] Ghai CL. A Textbook of Practical Physiology. 7th Edition, Jaypee Brothers Medical Publishers Ltd., New Delhi. 2007; 419.

[29] Schurig JE, Florczyk AP, Bradner WT. The mouse as a model for predicting the myelosuppressive effects of anticancer drugs. Cancer Chemother Pharmacol. 1973;16:243-6.

[30] Duncan R, Coatsworth JK, Burtles S. Preclinical toxicology of a novel polymeric antitumour agent: HPMA copolymerdoxorubicin (PK1). Hum Exp Toxicol. 1998;17:93-104.

[31] Van Vleet JF, Ferrans VJ. Clinical and pathologic features of chronic adriamycin toxicosis in rabbits. Am J Vet Res. 1980;41:1462-9.

[32] Klimtova I, Simunek T, Mazurova Y, Hrdina R, Gersl V. Comparative study of chronic toxic effects of daunorubicin and doxorubicin in rabbits. Hum Exp Toxicol. 2000;21:649-57.

[33] O'Keefe DA, Schaeffer DJ. Hematologic toxicosis associated with doxorubicin administration in cats. J Vet Intern Med. 1992;6:276-82.

[34] Susaneck SJ. Doxorubicin therapy in the dog. J Am Vet Med Assoc. 1983;182:70-2.

[35] Working PK, Dayan AD. Pharmacological-toxicological expert report CAELYX (stealth liposomal doxorubicin HCl). Hum Exp Toxicol. 1996;15:752-85. 
[36] Benjamin RS, Wiernik PH, Bachur NR. Adriamycin chemotherapy; efficacy, safety, and pharmacologic basis of an intermittent single high-dosage schedule. Cancer. 1974;33: 19-27.

[37] Richardson DS, Johnson SA. Anthracyclines in haematology: preclinical studies, toxicity and delivery systems. Blood Rev. 1997;11:201-23.

[38] Bonadonna G, Monfardini S, De Lena M, Fossati-Bellani F. Clinical evaluation of adriamycin, a new antitumour antibiotic. Br Med J. 1969;3:503-6.

[39] Falkson G, Klein B, Falkson H. Hematological toxicity: experience with anthracyclines and anthracenes. Exp Hematol. 1985; 13(16):64-71.

[40] Maral RJ, Jouanne M. Toxicology of daunorubicin in animals and man. Cancer Treat Rep. 1981;65 (4):9-18.

[41] Aggarwal BB, Kumar A, Bharti AC. Anticancer Research 2003; 23: 363-398.

[42] Sreejayan-Rao M. Curcuinoids as potent inhibitors of lipid peroxidation. J. Pharm. Pharmacol. 1994; 46: 10131016. 